УДК 619:618. 14-085

https://doi.org/10.32634/0869-8155-2021-347-4-60-65

Краткий обзор/Brief review

Серякова А.А. ${ }^{1}$,

Панов В.П. 1

Просекова Е.А. 1

Комарчев A.C. ${ }^{2}$,

Воронин К.0. ${ }^{3}$

Цветкова В.А. ${ }^{3}$

1 ФГБОУ ВО РГАУ - МСХА имени К.А. Тимирязева, кафедра морфологии и ветеринарно-санитарной экспертизы,

127550, г. Москва, ул. Тимирязевская, д. 44

E-mail: panovval@gmail.com

2 ФНС «ВНИТИП» РАН, отдел селекции и генетики, 141311, Московская обл., г. Сергиев Посад, ул. Птицеградская, д. 10

E-mail: kas1380@bk.ru

3 ООО «СИВЕТРА-АГРО» официальный представитель завода «Tanin Sevnica d.d.» в РФ,

125424, г. Москва, Волоколамское шоссе,

д. 73,

E-mail:k.voronin@sivetra-agro.ru

Ключевые слова: кишечник, эллаготани ны, птицеводство, кормление, бройлеры слизистая оболочка, ворсинки, пищеварение

Для цитирования: Серякова А.А., Панов В.П., Просекова Е.А., Комарчев А.С., Воронин К.О., Цветкова В.А. Влияние кормовой добавки Бутитан (Фарматан BCO) на гистофизиологическое состояние кишечной трубки и продуктивные качества цыплят-бройлеров. Аграрная наука. 2021 347 (4): 60-65.

https://doi.org/10.32634/0869-8155-2021-347-4-60-65

Конфликт интересов отсутствует

Aleksandra A. Seryakova ${ }^{1}$,

Valery P. Panov ${ }^{1}$,

Elena A. Prosekova ${ }^{1}$,

Alexey S. Komarchev'2

Kirill O. Voronin ${ }^{3}$,

Valeria A. Tsvetkova ${ }^{3}$

${ }^{1}$ FSBEI HE RSAU-MTAA named after K.A. Timiryazev department of morphology and veterinary and sanitary expertise, 127550

Moscow, Timiryazevskaya str., 44

E-mail:panovval@gmail.com

${ }^{2}$ FRC «ARSRIPPI» RAS department of breeding and genetics, 141311, Moscow Region, Sergiev Posad, Ptitsegradskaya str., 10

E-mail: kas1380@bk.ru

${ }^{3}$ LLC «SIVETRA-AGRO» official representative of the plant "Tanin sevnica» in the RF, 125424 Moscow, Volokolamsk highway, 73

E-mail:k.voronin@sivetra-agro.ru

Key words: intestine, ellagotannins, poultry farming, feeding, broilers, mucous membrane, villi, digestion

For citation: Seryakova A.A., Panov V.P. Prosekova E.A., Komarchev A.S. Voronin K.O., Tsvetkova V.A. The effect of the feed additive Butitan (Farmatan BCO) on the histophysiological state of the intestinal tube and the productive qualities of broiler chickens. Agrarian Science. 2021; 347 (4) 60-65. (In Russ.)

https://doi.org/10.32634/0869-8155-2021-347-4-60-65

There is no conflict of interests
Влияние кормовой добавки Бутитан (Фарматан ВСО) на гистофизиологическое состояние кишечной трубки и продуктивные качества цыплят-бройлеров

\begin{abstract}
РЕЗЮМЕ
Изучено влияние препарата Бутитан (Фарматан ВСО) на продуктивные качества и структуру стенки кишечника бройлеров. Суточные бройлеры разделены на группы численностью 60 голов. Контрольная группа получала основной рацион. Опытные группы получали с основным рационом добавки Бутитана: 1-я опытная группа - 250 г/т, 2-я опытная - 500 г/т и 3-я - 750 г/т. Продолжительность эксперимента: 42 дня. Учитывали живую массу и затраты корма. По достижении 42 дней проводился убой птицы, анатомическая разделка, отбор образцов для гистологических исследований. Проведен химический анализ грудных и ножных мышц. По живой массе птица опытных групп превосходила контрольных на $7,9 \%(P \leq 0,05)$, $8,2(P \leq 0,01)$ и $8,1 \%(P \leq 0,01)$. При этом затраты корма на 1 кг прироста ниже на $2,4 \% ; 3,8 \%$ и 1,4\% в первой, второй и третьей опытных группах. В опытных группах возрастает масса потрошеной тушки на 6,7-15,0\%. Наблюдается тенденция к увеличению содержания жира в грудных мышцах птиц опытных групп. Гистологическими методами установлено, что в двенадцатиперстной кишке бройлеров снижалась высота слоя ворсинок и толщина стенки кишки при лучшей сохранности эпителия, и большей выраженности лимфоидной ткани. В тощей и проксимальном участке слепой кишок высота слоя ворсинок выше в среднем на 11,1 и 19,3\%. Однако, в тощей кишке наблюдалась лучшая сохранность эпителиальной выстилки. Ворсинки участвуют во всасывании питательных веществ и способствуют эффективному использованию рациона. Поэтому все опытные группы имели большую живую массу при меньших затратах корма по сравнению с контролем.
\end{abstract}

\section{The effect of the feed additive Butitan (Farmatan BCO) on the histophysiological state of the intestinal tube and the productive qualities of broiler chickens}

\begin{abstract}
The effect of the feed additive Butitan (Farmatan BCO) on the productive qualities and structure of the intestinal wall of broilers was studied. Daily broilers are divided into groups of 60 heads. The control group received the main diet. The experimental groups received Butitan supplements with the main diet: 1 st experimental group $-250 \mathrm{~g} / \mathrm{t}$, 2nd experimental $-500 \mathrm{~g} / \mathrm{t}$ and the third $-750 \mathrm{~g} / \mathrm{t}$. The duration of the experiment was 42 days. The live weight and feed 3rd were taken into account. Upon reaching 42 days poultry was slaughtered, anatomical cutting and samples were taken for histological studies. A chemical analysis of the pectoral and leg muscles was performed. In terms of live weight, the poultry of the experimental groups exceeded the control groups by $7,9 \%(P \leq 0.05), 8,2(P \leq 0.01)$ and $8,1 \%(P \leq 0.01)$. At the same time, feed costs per $1 \mathrm{~kg}$ of growth are lower by $2,4 \% ; 3,8 \%$ and $1,4 \%$ respectively in the first, second and third experimental groups. In the experimental groups the weight of the gutted carcass increases by $6,7-15,0 \%$. There is a tendency to increase the fat content in the pectoral muscles of birds of the experimental groups. Histological methods revealed that in the duodenum of broilers, the height of the villi layer and the thickness of the intestinal wall decreased with better preservation of the epithelium and greater severity of the lymphoid tissue. In the jejunum and proximal part of the caecum, the height of the villi layer is higher on average by 11,1 and $19,3 \%$. However, better preservation of the epithelial lining was observed in the jejunum. The villi are involved in the absorption of nutrients and contribute to the effective use of the diet. Therefore, all the experimental groups had a large live weight with lower feed costs compared to the control.
\end{abstract}




\section{Введение}

На сегодняшний день представлен широкий ассортимент различного рода препаратов, призванных решать проблемы, связанные с работой желудочно-кишечного тракта птицы, и улучшать производственные показатели предприятий. К таким препаратам относятся антибиотики, пробиотики, пребиотики и т.д. В последнее время в птицеводстве все чаще стали применяться препараты растительного происхождения. Они представляют собой альтернативу использованию антибиотиков, которые аккумулируются в организме животных и тем самым снижают качество производимой продукции и, прежде всего, продуктов питания [1, 2, 3]. Растительные кормовые добавки используются для улучшения переваримости, конверсии корма, стимуляции роста и повышения продуктивности животных $[4,5,6,7,8]$. Помимо этого, добавки растительного происхождения оказывают положительное стабилизирующее действие на микрофлору кишечника, обладают антимикробными свойствами $[9,10,11,12,13]$

Ряд работ связан с влиянием растительных добавок на процессы пищеварения и активизации ферментов в органах желудочно-кишечного тракта [8, 14, 15 , $16,17,18,19,20]$. Усвоение пищи непосредственно связано с морфологическим строением органов желудочно-кишечного тракта. В последнее время проведен ряд исследований, посвященных гистоструктуре различных отделов пищеварительной системы животных, получавших добавки растительного происхождения, содержащие танины [20, 21, 22, 23]. Надо учитывать, что комплексные препараты, как правило, действуют более эффективно, чем каждый компонент по отдельности [2].

К таким препаратам относится Бутитан (Фарматан ВСО). В его основе экстракт древесины сладкого каштана (содержащий органические кислоты, моно- и полисахариды, эфирные масла, макро- и микроэлементы) и бутират кальция. Препарат выпускается в микрокапсулированном виде, чтобы защитить действующие вещества от распада в верхних отделах ЖКТ. Применение кормовой добавки Бутитан (Фарматан ВСО) является актуальным в такой интенсивно развивающейся отрасли животноводства, как птицеводство. Исследования, связанные с оценкой действия Бутитана на организм птиц, показали его эффективность: повышаются выживаемость, приросты и конечная масса бройлеров [24]. На сегодняшний день в литературе нет данных о воздействии непосредственно Бутитана на гистоструктуру кишечной трубки бройлеров. В связи с этим цель нашего исследования заключалась в установлении влияния различных дозировок кормовой добавки Бутитан (Фарматан ВСО) на гистофизиологическое состояние стенки некоторых отделов тонкого и толстого кишечника и продуктивные качества цыплят-бройлеров.

\section{Методика}

Опыт по установлению влияния препарата Бутитан (Фарматан ВСО) на гистоструктуру различных отде- лов пищеварительной системы бройлеров проводился в условиях учебно-опытного птичника РГАУ - МСХА имени К.А. Тимирязева. Суточные цыплята кросса «Смена-8» разделялись на группы методом пар-аналогов по живой массе. Схема эксперимента представлена в таблице 1.

Бутитан (Фарматан ВСО) в рацион птиц вносился при изготовлении корма. При выращивании бройлеров стимуляторы роста и антибиотики не использовали и вакцинация птиц не проводилась. Состав рациона приведен в таблице 2 .

Бройлеры содержались в клеточных батареях «Фаэтон» при круглосуточном освещении. Параметры микроклимата поддерживались в пределах норм.

Продолжительность эксперимента составляла 42 дня. На протяжении эксперимента учитывали живую массу и расход корма на прирост птиц. В конце эксперимента проводили анатомическую разделку бройлеров.

Для изучения химического состава мышц отбирали пробы из поверхностной грудной и икроножной мышц, в пробах определяли содержание воды при высушивании образцов при $105^{\circ} \mathrm{C}$ и жира в аппарате Сокслета.

Для гистологического анализа отбирали образцы из середины двенадцатиперстной, тощей и проксимального участка слепой кишок. Образцы помещали в 10\%-ный забуференный формалин, уплотняли, гистологические препараты изготавливали по стандартным методикам. На срезах определяли величину оболочек слоев трубкообразных органов. Поскольку толщина подслизистой и серозной оболочек чрезвычайно малы, при анализе гистоструктуры органов они не учитывались. Полученные данные обрабатывали статистически согласно стандартным методикам.

\section{Результаты}

Включение кормовой добавки Бутитан (Фарматан ВСО) в рацион при выращивании бройлеров приводит к

\section{Таблица 1. Схема эксперимента}

Table 1. Experiment diagram

\begin{tabular}{|c|c|c|}
\hline Группа & Количество голов, шт. & Рацион \\
\hline Контроль (К) & 60 & OP \\
\hline 1-я опытная (O1) & 60 & OP+250 г/т \\
\hline 2-я опытная (О2) & 60 & $\mathrm{OP}+500$ г/т \\
\hline 3-я опытная (О3) & 60 & $\mathrm{OP}+750$ г/т \\
\hline
\end{tabular}

Таблица 2. Состав основного рациона

Table 2. The composition of the main diet

\begin{tabular}{|c|c|}
\hline Компоненты & Количество корма, г \\
\hline Кукуруза & 58,5 \\
\hline Глютен кукурузный & 5 \\
\hline Рыбная мука & 11 \\
\hline Соевый шрот & 20 \\
\hline L-лизин & 0,25 \\
\hline DL-метионин & 0,25 \\
\hline Бетакорм & 0,5 \\
\hline Трикальцийфосфат & 1 \\
\hline Растительное масло & 3 \\
\hline Мел кормовой & 0,5 \\
\hline
\end{tabular}


Таблица 3. Морфометрия кишечника цыплят-бройлеров в 42 дня, мкм

Table 3. Intestinal morphometry of broiler chickens at $\mathbf{4 2}$ days, microns

\begin{tabular}{|c|c|c|c|c|c|c|}
\hline & \multicolumn{6}{|c|}{ Толщина слоев и оболочек } \\
\hline & ворсинки & крипты & $\begin{array}{l}\text { мышечная } \\
\text { пластинка } \\
\text { слизистой }\end{array}$ & слизистая & мышечная & стенка в целом \\
\hline \multicolumn{7}{|c|}{ Двенадцатиперстная кишка } \\
\hline $\mathrm{K}$ & $1805,5 \pm 28,5$ & $182,6 \pm 4,4$ & $30,2 \pm 1,2$ & $2018,3 \pm 30,6$ & $143,3 \pm 2,9$ & $2161,6 \pm 29,2$ \\
\hline 01 & $1643,1^{\star \star} \pm 17,7$ & $197,2 \pm 21,4$ & $29,1 \pm 1,2$ & $1869,5^{\star \star \star} \pm 28,7$ & $140,4 \pm 2,4$ & $2009,9^{\star} \pm 29,3$ \\
\hline $\mathrm{O} 2$ & $1664,9^{\star \star} \pm 15,0$ & $162,5^{\star} \pm 3,7$ & $25,9^{\star} \pm 0,9$ & $1853,3^{\star \star \star} \pm 16,2$ & $130,4^{\star} \pm 2,0$ & $1983,7^{\star \star} \pm 17,0$ \\
\hline $\mathrm{O} 3$ & $1665,8^{\star *} \pm 12,8$ & $159,7^{\star} \pm 3,8$ & $24,8^{\star} \pm 0,7$ & $1850,3^{\star * *} \pm 13,5$ & $117,7^{\star \star \star} \pm 2,1$ & $1967,6^{\star \star} \pm 13,5$ \\
\hline В среднем по опытным группам & 1657,9 & 173,1 & 26,6 & 1857,7 & 129,5 & 1987,1 \\
\hline \multicolumn{7}{|c|}{ Тощая кишка } \\
\hline $\mathrm{K}$ & $902,9 \pm 17,5$ & $110,1 \pm 4,3$ & $31,6 \pm 1,2$ & $1044,0 \pm 18,9$ & $162,7 \pm 4,5$ & $1206,7 \pm 21,0$ \\
\hline 01 & $1117,2^{\star \star \star} \pm 31,1$ & $99,2^{\star} \pm 2,9$ & $36,7^{\star \star} \pm 1,6$ & $1253,1^{\star \star \star} \pm 32,4$ & $137,4^{\star \star \star} \pm 2,8$ & $1390,5^{\star \star *} \pm 32,5$ \\
\hline $\mathrm{O} 2$ & $924,5 \pm 9,2$ & $86,2^{\star \star \star} \pm 2,4$ & $36,9^{\star \star} \pm 1,4$ & $1047,6 \pm 9,3$ & $142,7^{\star \star \star} \pm 3,4$ & $1190,3 \pm 10,7$ \\
\hline $\mathrm{O} 3$ & $970,4^{\star \star} \pm 14,3$ & $98,8^{\star} \pm 3,5$ & $32,8 \pm 1,3$ & $1102,0^{\star} \pm 15,2$ & $122,4^{\star \star \star} \pm 4,6$ & $1224,4 \pm 21,1$ \\
\hline В среднем по опытным группам & 1004,0 & 94,7 & 36,5 & 1134,2 & 134,2 & 1268,4 \\
\hline \multicolumn{7}{|c|}{ Слепая кишка } \\
\hline $\mathrm{K}$ & $746,1 \pm 25,2$ & $159,8 \pm 8,6$ & $28,5 \pm 1,2$ & $934,4 \pm 27,7$ & $245,6 \pm 7,6$ & $1179,9 \pm 29,7$ \\
\hline $\mathrm{O} 1$ & $861,2^{\star} \pm 17,5$ & $124,1^{\star} \pm 4,9$ & $30,7 \pm 1,2$ & $1016,0^{\star} \pm 20,5$ & $225,8 \pm 4,7$ & $1241,8 \pm 22,7$ \\
\hline $\mathrm{O} 2$ & $854,0 * \pm 20,4$ & $110,6^{\star \star} \pm 3,6$ & $33,8^{\star} \pm 1,6$ & $998,4 \pm 21,4$ & $249,4 \pm 8,8$ & $1247,8 \pm 20,6$ \\
\hline $\mathrm{O} 3$ & $955,6^{\star * \star} \pm 11,3$ & $106,0^{\star \star} \pm 2,6$ & $33,0^{\star} \pm 1,2$ & $1094,7^{\star \star \star} \pm 12,5$ & $218,8^{\star} \pm 3,6$ & $1313,5^{\star \star} \pm 14,0$ \\
\hline В среднем по опытным группам & 890,2 & 113,6 & 32,5 & 1036,4 & 231,3 & 1267,7 \\
\hline
\end{tabular}

ряду морфометрических изменений в стенке различных отделов кишечной трубки.

В двенадцатиперстной кишке толщина стенки уменьшается на 7,9$10,2 \%$ (в среднем на 9,1\%) по сравнению с контролем. Исключением, в некоторой степени, является вариант О1 с наименьшим содержанием препарата (250 мг/кг). В этом случае величина слоя крипт и мышечной пластинки слизистой не подвержена изменению в сторону уменьшения. При этом в среднем все абсолютные показатели стенки двенадцатиперстной кишки у бройлеров опытных групп ниже, чем в контроле.

В дистально расположенной тощей кишке наблюдаются некоторые изменения в строении стенки этого органа. Прежде всего это касается размера слоя ворсинок, величина которого выше, чем у бройлеров контрольной группы, на 2,4-23,7\% (в среднем на 11,1\%). Рост крипт и мышечной оболочки в тощей кишке несколько ниже, как и в двенадцатиперстной кишке.

В слепой кишке рост слоя ворсинок продолжается более интенсивно, особенно при высокой дозе Бутитана (Фарматана ВСО) в раци-
Таблица 4. Соотношение толщины оболочек и слоев кишечника (в \% от целой стенки) Table 4. The ratio of the thickness of the shells and layers of the intestine (in \% of the whole wall)

\begin{tabular}{|c|c|c|c|c|c|}
\hline & \multicolumn{5}{|c|}{ Толщина слоев и оболочек } \\
\hline & ворсинки & крипты & $\begin{array}{c}\text { мышечная } \\
\text { пластинка сли- } \\
\text { зистой }\end{array}$ & $\begin{array}{c}\text { слизистая в } \\
\text { целом }\end{array}$ & $\begin{array}{c}\text { мышечная } \\
\text { оболочка }\end{array}$ \\
\hline \multicolumn{6}{|c|}{ Двенадцатиперстная кишка } \\
\hline K & 83,5 & 8,5 & 1,4 & 93,4 & 6,6 \\
\hline O1 & 82,2 & 9,3 & 1,4 & 92,9 & 7,1 \\
\hline $\mathrm{O} 2$ & 83,9 & 8,2 & 1,3 & 93,4 & 6,6 \\
\hline O3 & 84,6 & 8,1 & 1,3 & 94,0 & 6,0 \\
\hline Cp.O & 83,6 & 8,5 & 1,3 & 93,4 & 6,6 \\
\hline \multicolumn{6}{|c|}{ Тощая кишка } \\
\hline $\mathrm{K}$ & 74,7 & 9,1 & 2,7 & 86,5 & 13,5 \\
\hline O1 & 79,8 & 7,3 & 2,7 & 89,7 & 10,3 \\
\hline $\mathrm{O} 2$ & 77,7 & 7,2 & 3,1 & 88,0 & 12,0 \\
\hline $\mathrm{O} 3$ & 79,3 & 8,1 & 2,7 & 90,0 & 10,0 \\
\hline Cp.O & 78,9 & 7,5 & 2,8 & 89,2 & 10,8 \\
\hline \multicolumn{6}{|c|}{ Слепая кишка } \\
\hline $\mathrm{K}$ & 62,3 & 13,6 & 2,5 & 78,3 & 21,7 \\
\hline O1 & 69,2 & 9,9 & 2,5 & 81,6 & 18,4 \\
\hline $\mathrm{O} 2$ & 68,2 & 8,8 & 2,8 & 79,7 & 20,3 \\
\hline $\mathrm{O} 3$ & 72,7 & 8,1 & 2,5 & 83,3 & 16,7 \\
\hline Cp.O & 70,0 & 8,9 & 2,6 & 81,5 & 18,5 \\
\hline
\end{tabular}


оне бройлеров (на 28,1\% по сравнению с контрольной группой). У опытных групп бройлеров слой крипт развит существенно слабее, чем у птиц контрольной группы (в среднем на 40,6\%). Слой сократительных элементов (мышечная ткань) в слизистой слепой кишки под влиянием Бутитана (Фарматана ВСО) выражен сильнее.

Величина количественных абсолютных показателей связана в определенной степени не только с применяемым фактором, но и непосредственно с ростом животного. Поэтому для более объективного суждения о полученных данных необходимо анализировать и относительные, в виде соотношения структур, входящих в состав стенки трубкообразных органов (таблица 4).

Введение в рацион Бутитана (Фарматана ВСО) в различных дозах не оказало заметного влияния на соотношение морфологических структур в стенке двенадцатиперстной кишки. Слизистая и мышечная оболочки этого отдела кишечника бройлеров находятся в соответствии с контрольной группой птиц.

В тощей кишке под влиянием Бутитана (Фарматана ВСО) наблюдается сдвиг в сторону увеличения толщины слизистой за счет ворсинок (с 74,7 до 77,7-79,9\%) при уменьшении слоя крипт. Более тонким становится мышечная оболочка стенки кишечника. Аналогичные изменения в соотношении гистоструктур наблюдаются в стенке проксимального отдела слепой кишки.

При изучении тотальных препаратов у бройлеров, получавших Бутитан (Фарматан ВСО), отмечены лучшее развитие лимфоидной ткани, отвечающей за иммунитет птиц. Также у опытных бройлеров сохранность эпителия ворсинок двенадцатиперстной кишки лучше - его целостность сохранена по всей площади (рис. 1, 2). В контрольной группе на апикальной части ворсинок эпителий отходит от стромы и при большей величине ворсинок не вся их поверхность функциональна (рис. 3). В слое ворсинок тощей кишки также отмечено большее количество лимфоидной ткани. Эпителий ворсинок у бройлеров О1 и О2 характеризуется большей сохранностью. В проксимальном отделе слепой кишки внесение Бутитана (Фарматана ВСО) в рацион птиц не оказывает влияния на развитие лимфоидных образований, но увеличивает сохранность эпителия ворсинок.

Помимо этого, кормовая добавка Бутитан (Фарматан ВСО) оказывают влияние на зоотехнические показатели. В первые три недели выращивания различий по живой массе между опытными и контрольными группами нет. В дальнейшем птица опытных групп опережает контрольных по приросту живой массы. В конце эксперимента разница между контрольной и О1, О2 и О3 coставляет 7,9\% $(P \leq 0,05), 8,2(P \leq 0,01)$ и $8,1 \%(P \leq 0,01)$ соответственно. При этом затраты корма на 1 кг прироста были ниже на 2,4\%; 3,8\% и 1,4\% соответственно в первой, второй и третьей ОГ.

Результаты разделки тушек показывают, что в опытных группах возрастает масса потрошеной тушки: в О1 - на $11,4 \%(P \leq 0,05)$, в О2 - на $15,0 \%(P \leq 0,01)$ и в О3 - на $6,7 \%(P \leq 0,05)$. Масса грудных мышц увеличивается в 01 на 63 грамма, что составляет 24,8\% $(P \leq 0,05)$, а в 02 - на 44 грамма. Масса ножных мышц в О1 и О2 имеет тенденцию к увеличению. По массе кожи (с подкожным жиром) и субпродуктов (печень, сердце, мышечный желудок) не выявлено отличий между группами. Масса кишечника в О1 достоверно ниже на 11,5\% (табл. 5).

Содержание воды в левой поверхностной грудной мышце колебалось в пределах 74,25-75,81\%. Содержание сухого вещества в грудных мышцах цыплят опытных
Pис. 1. Сохранность ворсинок в опытных группах. Окраска гематоксилин-эозином, ув. объектив х8, окуляр х10: 1 ворсинки, 2 - крипты, 3 - эпителий

Fig. 1. Preservation of villi in experimental groups. Hematoxylin-eosin staining, uv. lens $\times 8$, eyepiece $\times 10: 1$ - villi, 2 - crypts, $3-$ epithelium

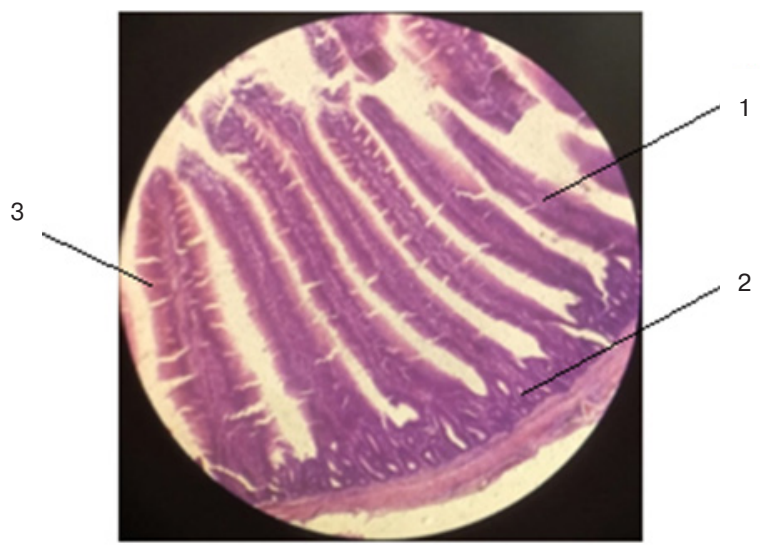

Pис. 2. Лимфоидная ткань в опытных группах. Окраска гематоксилин-эозином, ув. объектив х20, окуляр х10: 1 - ворсинки, 2 - лимфоидная ткань, 3 - крипты, 4 мышечная оболочка

Fig. 2. Lymphoid tissue in experimental groups. Hematoxylin-eosin staining uv. lens $\times 20$, eyepiece x10: 1 - villi, 2 - lymphoid tissue, 3 - crypts, 4 - muscular layer

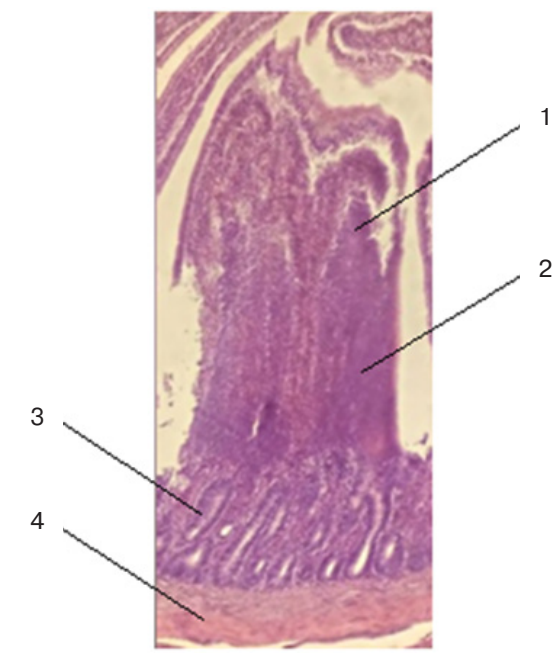

Рис. 3. Деформация стромы в апикальной части ворсинок, контрольная группа. Окраска гематоксилин-эозином, ув. объектив х8, окуляр х10: 1 - деформация эпителия, 2 ворсинки, 3 - крипты

Fig. 3. Stroma deformity in the apical part of the villi of control group. Hematoxylin-eosin staining, uv. lens x8, eyepiece x10: 1 - stroma deformity, 2 - villi, 3 - crypts

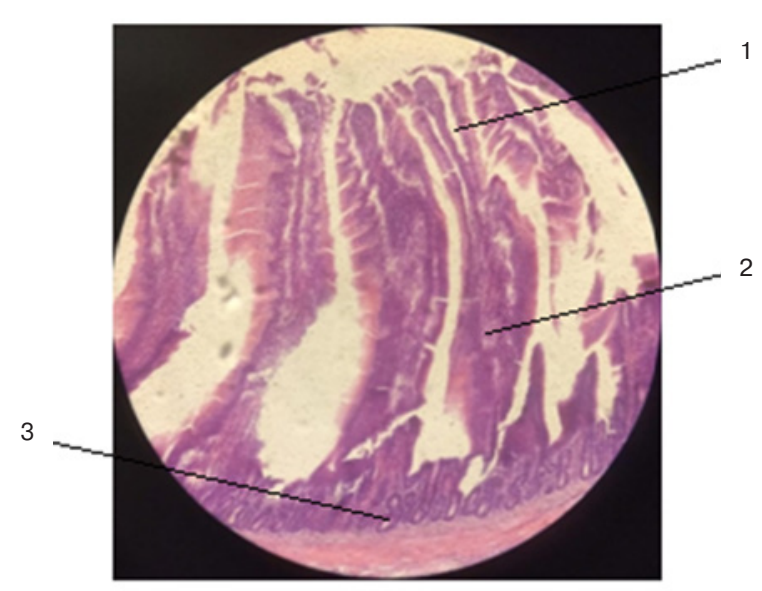




\begin{tabular}{|c|c|c|c|c|c|c|c|c|}
\hline \multirow[b]{2}{*}{ Группа } & \multicolumn{8}{|c|}{ Macca, $r$} \\
\hline & $\begin{array}{l}\text { потрошен- } \\
\text { ная тушка }\end{array}$ & $\begin{array}{c}\text { кожа с } \\
\text { подкожным } \\
\text { жиром }\end{array}$ & $\begin{array}{c}\text { грудные } \\
\text { мышцы }\end{array}$ & $\begin{array}{l}\text { ножные } \\
\text { мышцы }\end{array}$ & печень & сердце & $\begin{array}{c}\text { мышечный } \\
\text { желудок }\end{array}$ & кишечник \\
\hline $\mathrm{K}$ & $1247 \pm 14$ & $149 \pm 18,0$ & $257 \pm 8,3$ & $278 \pm 11,6$ & $41,3 \pm 3,0$ & $10,1 \pm 0,6$ & $20,7 \pm 2,7$ & $89,5 \pm 0,6$ \\
\hline O1 & $1390^{\star} \pm 36$ & $172 \pm 16,5$ & $320^{\star \star} \pm 9,7$ & $295 \pm 17,7$ & $44,3 \pm 2,3$ & $9,2 \pm 0,3$ & $21,3 \pm 2,2$ & $79,2 \pm 4,8$ \\
\hline $\mathrm{O} 2$ & $1435^{\star \star \star} \pm 22$ & $146 \pm 2,2$ & $301 \pm 17,5$ & $309 \pm 9,4$ & $49,1 \pm 4,1$ & $9,0 \pm 0,5$ & $22,3 \pm 2,4$ & $89,6 \pm 4,0$ \\
\hline $\mathrm{O} 3$ & $1331^{\star *} \pm 6$ & $163 \pm 10,7$ & $278 \pm 16,3$ & $240 \pm 51,9$ & $40,9 \pm 1,4$ & $9,5 \pm 0,3$ & $18,3 \pm 1,2$ & $114,6 \pm 14,3$ \\
\hline
\end{tabular}

групп превышало контроль на 1,56; 0,24 и 0,57\%. Наблюдалось увеличение содержания жира в 1-й и 2-й опытной группе на 0,38 и $0,15 \%$ и снижение в 3-й опытной группе на 0,21\% относительно контроля (табл. 6).

Содержание воды в левой икроножной мышце колебалось в пределах 76,91-77,69\%. Содержание сухого вещества в икроножных мышцах цыплят опытных групп превышало контроль на 0,44, 0,06 и 0,78\%. Наблюдалось снижение содержания жира во 2-й опытной группе на $0,36 \%$ относительно контроля.

\section{Заключение}

Реакция оболочек и слов стенки различных отделов кишечной трубки бройлеров связана с особенностями их строения и функций. Двенадцатиперстная кишка птиц, находясь в авангарде, принимает на себя более концентрированные порции препарата, чем следующие за ней отделы кишечника. Ответ у дуоденальной слизистой оболочки выражен в снижении абсолютных, но не относительных значений толщины слоев ворсинок и крипт. Соотношение оболочек и слоев стенки в двенадцатиперстной кишке по сравнению с контрольной группой не изменяется. При этом Бутитан (Фарматан ВСО) благоприятно влияет на эпителиальную выстилку ворсинок. Здесь также наблюдаются скопления лимфоидной ткани. Тощая кишка и проксимальный отдел слепой кишки расположены более дистально относительно продвигающейся пищи с компонентами Бутитана (Фарматана ВСО). Его воздействие здесь положительно сказывается на развитии ворсинок слизистой оболочки, но не крипт, толщина слоя которых уменьшается. Это, по нашему мнению, связано с тем, что крипты обеспечивают образование эпителиальной выстилки ворсинок, и поскольку в опытных группах таковая не нарушена, мы полагаем, что снижение величины слоя крипт не сказалось на их функции. Мышечная

\section{ЛИТЕРATУPA/ REFERENCES.}

1. Юнаева Н.В., Саландиев К.В., Слюсарь А.В. Масло орегано заменяет антибиотики в птицеводстве. Птицеводство. 2016;8:43-47. [Yunaeva N. V., Salandiev K. V., Slyusar A.V. Oregano Oil: An alternative to antibiotics for poultry. Pticevodstvo. 2016;8:43-47. (In Russ.)].

2. Багно О.А., Прохоров О.Н., Шевченко С.А.,2, А.И. Шевченко А.И. Дядичкина Т.В. Фитобиотики в кормлении сельскохозяйственных животных. Сельскохозяйственная биология. 2018:53(4):687-697. [Bagno О. A., Prokhorov O. N., Shevchenko S. A., 2, A. I. Shevchenko A. I., Dyadichkina T. V. Use of phytobioticts in farm animal feeding. Selskohozyajstvennaya оболочка стенки несколько истончается в абсолютном и относительном выражении. Снижение относительной величины мышечной оболочки при увеличении слоя ворсинок отмечено в исследованиях, например, при внесении в рацион молочно-кислых заквасок. Такие изменения в соотношении слоев кишечника не сказались на продуктивных качествах бройлеров [25].

Положительное действие Бутитана (Фарматана ВСО) проявляется наибольшим образом в тощей кишке, наиболее значимой для всасывания питательных веществ корма. Видимо, здесь происходит интенсивная пролиферация эпителия в криптах, что обеспечивает рост ворсинок у бройлеров опытных групп. В свою очередь ворсинки участвуют во всасывании питательных веществ и способствуют эффективному использованию рациона для роста массы птиц. Таким образом, лучшее развитие ворсинок в группах, принимавших кормовую добавку Бутитан (Фарматан ВСО), объясняет, почему все опытные группы имели большую живую массу при меньших затратах корма по сравнению с контролем. Для определения оптимальной дозировки препарата необходимы дальнейшие исследования (микробиологические, гематологические, морфо-физиологические).

biologiya. 2018;53(4):687-697. (In Russ.)]

3. Федотов В.А., Никитченко В.Е., Никитченко Д.В., Егоров И.А., Егорова Т.В. Пробиотики в кормлении птицы. Птицеводство, 2018;8:33-37. [Fedotov V. A., Nikitchenko V. E., Nikitchenko D. V., Egorov I. A., Egorova T. V. Probiotics in poultry feeding. Pticevodstvo. 2018;8:33-37. (In Russ.)].

4. Багиров В.А., Дускаев Г.К., Казачкова Н.М., Рахматуллин Ш.Г., Яушева Е.В., Косян Д.Б., Макаев Ш.А., Дусаева Х.Б. Включение экстракта Quercus cortex в рацион бройлеров изменяет их убойные показатели и биохимический состав мышечной ткани. Сельскохозяйственная биологии. 2018;53(4):799-810. [Bagirov V. A., Duskaev G. K., Kazachkova N. M., Rakhmatullin Sh. G., Yausheva E. V., Kosyan D. B., Makaev 
Sh. A., Dusaeva Kh. B. Addition of Quercus cortex extract to broiler diet changes slaughter indicators and biochemical composition of muscletissue. Selskohozyajstvennaya biologiya. 2018;53(4):799810. (In Russ.)].

5. Игнатович Л.С. Влияние применения компонентных кормовых добавок, изготовленных с применением травяной муки из тысячелистника обыкновенного, на продуктивность кур-несушек, качество производимой продукции (яиц) и конверсию корма. Дальневосточный аграрный вестник. 2017;2:75-81. [Ignatovich L.S. Influence of use of component feed additives, manufactured with the use of grass meal of yarrow, on laying hens productivity, quality of the products (eggs) and feed conversion. Dalnevostochnyj agrarnyj vestnik. 2017;2:75-81. (In Russ.)].

6. Бушов А.В., Курманаева В.В. Биопрепараты в рационах цыплят-бройлеров кросса Смена 7. Птицеводство. 2012;1:3133. [Bushov A.V., Kurmanaeva V. V. Bio-preparations in diets for Smena-7 broilers. Pticevodstvo. 2012;1:31-33. (In Russ.)].

7. Duskaev GK, Kazachkova NM, Ushakov AS, Nurzhanov BS, Rysaev AF. The effect of purified Quercus cortex extract on biochemical parameters of organism and productivity of healthy broiler chickens. Veterinary World. 2018;11:235-239.

8. Longstaf $M$, McNab JM. The inhibitory effects of hull polysaccharides and tannins of field beans (Vicia faba L.) on the digestion of amino acids, starch and lipid and on digestive enzyme activities in young chicks. British Journal of Nutrition. 1991;65:199216.

9. Juliano C, Mattana A, Usai M. Composition and in vitro antimicrobial activity of the essential oil of Thymus herba-barona Loisel growing wild in Sardinia. Essent. Oil Res. 2000;12:516-522.

10. Marino M, Bersani C, Comi G. Antimicrobial activity of the essential oils of Thymus vulgaris $L$. measured using a bioimpedometric method. Food Protect. 1999; 62:1017-1023.

11. Si W, Gong J, Tsao R, Zhou T, Yu H, Poppe C, Johnson R, Du Z. Antimicrobial activity of essential oils and structurally related synthetic food additives towards selected pathogenic and beneficial gut bacteria. Applied Microbiology. 2006;100:296-305.

12. Dorman HJ, Deans SG. Antimicrobial agents from plants: antimicrobial activity of plant volatile oils. Applied Microbiology. 2000;88:308-316

13. Baratta MT, Dorman HJ, Deans SG, Biondi DM, Ruberto G. Chemical composition, antimicrobial and antioxidative activity of laurel, sage, rosemary, oregano and coriander essentials oils. Essen. Oil Res. 1998;10:618-627.

14. Hagerman AE, Butler LG. Determination of protein in tannin-protein precipitate. Agric Food Chem. 1980;28(5):944-94.

15. Макаева А.М., Атландерова К.Н. Переваримость питательных веществ корма при использовании биостимулятора экстракта коры дуба (Quercus cortex) в условиях in vitro. Жи-

\section{ОБ АВТОРАХ:}

Панов Валерий Петрович, д. б. н., профессор, ФГБОУ ВО РГАУ - МСХА имени К.А. Тимирязева кафедра морфологии и ветеринарно-санитарной экспертизы, профессор кафедры морфологии и ветеринарно-санитарной экспертизы.

Просекова Елена Александровна, к.б.н., доцент, ФГБОУ ВО РГАУ - МСХА имени К.А. Тимирязева кафедра морфологии и ветеринарно-санитарной экспертизы, доцент кафедры морфологии и ветеринарно-санитарной экспертизы.

Серякова Александра Андреевна, ФГБОУ ВО РГАУ - МСХА имени К.А. Тимирязева кафедра морфологии и ветеринарно-санитарной экспертизы, аспирант кафедры морфологии и ветеринарно-санитарной экспертизы.

Комарчев Алексей Сергеевич, к.с.-Х.н., ФНС «ВНИТИП» РАН, старший научный сотрудник отдела селекции и генетики ФНС «ВНИТИП» РАН

Воронин Кирилл Олегович, ООО “СИВЕТРА-АГРО» официальный представитель завода «Tanin sevnica» в РФ, специалист по птицеводству ООО «СИВЕТРА-АГРО».

Цветкова Валерия Андреевна, ООО «СИВЕТРА-АГРО» официальный представитель завода «Tanin sevnica» в РФ, зам. генерального директора ООО «СИВЕТРА-АГРО». вотноводство и кормопроизводство. 2018;101(1):147-153. [Makaeva A.M., Atlanderova K.N. Digestibility of feed nutrients after using bio-stimulant extract of oak cortex (Quercus cortex ) in vitro. Zhivotnovodstvo i kormoproizvodstvo. 2018;101(1):147153. (In Russ.)].

16. Griffiths DW, Moseley G. Effect of diet containing field beans of high and low polyphenolic content on the activity of digestive enzymes in the intestine of rats. Sci. Food Agric. 1980;31:255-259.

17. Horigome T, Kumar R, Okamoto K. Effect of condensed tannins prepared from leaves of fodder plants on digestive enzymes in vitro and in the intestine of rats. British Journal of Nutrition. 1988;60:275-285

18. Ahmed $A E$, Smtthard R, Ellis M. Activities of enzymes of the pancreas, and the lumen and mucosa of the small intestine in growing broiler cockerels fed on tannin-containing diets. British Journal of Nutrition. 1991;65:189-197.

19. Mangan JL. Nutritional effects of tannins in animal feeds. Nutr. Res. Rev. 1981;1:209-231.

20. Ortiz LT, Alzueta C, Trevino J, Castano M. Effects of faba bean tannins on the growth and histological structure of the intestinal tract and liver of chicks and rats. Brit. Poult. Sci. 1994;35:743-754

21. Oso AO, Suganthi RU, Manjunatha Reddy GB, Malik PK, Thirumalaisamy G, Awachat VB, Selvaraju S, Arangasamy A Bhatta R. Effect of dietary supplementation with phytogenic blend on growth performance, apparent ileal digestibility of nutrients, intestinal morphology, and cecal microflora of broiler chickens. Poultry Science. 2019;98:4755-4766.

22. Jamroz D, Wertelecki T, Houszka M, Kamel C. Influence of diet type on the inclusion of plant origin active substances on morphological and histochemical characteristics of the stomach and jejunum walls in chicken. Anim. Physiol. Anim. Nutr. 2006;90 P.255-268.

23. Dibner JJ, Kitchell ML, Atwell CA, Ivey FJ. The effects of dietary ingredients and age on the microscopic structure of the gastrointestinal tract in poultry. Appl. Poult. Res. 1996;5:70-77.

24. Буяров В.С., Червонова И.В., Меднова В.В, Ильичева И.Н. Эффективность применения фитобиотиков в птицеводстве (обзор). Вестник аграрной науки. 2020;3(84):4459. [Buyarov V.S., Chervonova I.V., Mednova V.V, II'icheva I.N Efficiency of application of phytobiotics in poultry farming (review) Vestnik agrarnoj nauki. 2020;3(84):44-59. (In Russ.)].

25. Просекова ЕА. Рост и морфофункциональное состояние органов и тканей бройлеров, выращенных с использованием пробиотиков. М. : РГАУ-МСХА. 2011. 200 с. [Prosekova EA. Growth and morphofunctional state of organs and tissues of broilers grown with probiotics. M. : RGAU-MSHA. 2011. 200 p. (In Russ.)].

\section{ABOUT THE AUTHORS:}

Panov Valery Petrovich, Doc. Sci. (Biological), Professor, FSBE HE RSAU-MTAA named after K. A. Timiryazev department of morphology and veterinary and sanitary expertise, Professor at the department of morphology and veterinary and sanitary expertise. Prosekova Elena Aleksandrovna, Cand. Sci. (Biological), Docent, FSBEI HE RSAU-MTAA named after K. A. Timiryazev department of morphology and veterinary and sanitary expertise, Associate Professor at the department of morphology and veterinary and sanitary expertise.

Seryakova Aleksandra Andreevna, FSBEl HE RSAU-MTAA named after K. A. Timiryazev department of morphology and veterinary and sanitary expertise, Postgraduate at the department of morphology and veterinary and sanitary expertise.

Komarchev Alexey Sergeevich, Cand. Sci. (Agriculture), FRC "ARSRIPPI» RAS department of breeding and genetics, Senior research officer department of breeding and genetics FRC «ARSRIPPI»RAS.

Voronin Kirill Olegovich, LLC «SIVETRA-AGRO» official representative of the plant «Tanin sevnica» in the RF, poultry specialist LLC «SIVETRA-AGRO».

Tsvetkova Valeria Andreevna, LLC «SIVETRA-AGRO» official representative of the plant «Tanin sevnica» in the RF, Deputy general director LLC «SIVETRA-AGRO». 